E3S Web of Conferences 1, 07004 (2013)

DOI: $10.1051 / \mathrm{e} 3$ sconf/20130107004

(c) Owned by the authors, published by EDP Sciences, 2013

\title{
Evaluation of the nanoparticles contribution to elemental concentration in airborne particulate matter
}

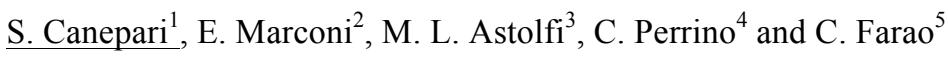 \\ ${ }^{1}$ Chemistry Department, Sapienza University of Rome, 00185 Rome, ITALY, silvia.canepari@uniroma1.it \\ ${ }^{2}$ Chemistry Department, Sapienza University of Rome, 00185 Rome, ITALY, elisabetta.marconi@uniroma1.it \\ ${ }^{3}$ Chemistry Department, Sapienza University of Rome, 00185 Rome, ITALY, marialuisa.astolfi@uniroma1.it \\ ${ }^{4}$ Institute of Atmospheric Pollution (IIA), C.N.R., 00016 Monterotondo, Rome, ITALY, perrino@iia.cnr.it \\ ${ }^{5}$ Chemistry Department, Sapienza University of Rome, 00185 Rome, ITALY, carmela.farao@uniroma1.it
}

\begin{abstract}
A method for estimating the contribution of nanoparticles (NPs) to the elemental concentration in airborne particulate matter (PM) is described. The results related to size-segregated samples collected at an urban site show that significant concentrations of $\mathrm{Sb}, \mathrm{Cd}, \mathrm{Pb}, \mathrm{As}, \mathrm{V}$ and $\mathrm{Sn}$ are present in the fine fraction of PM as complex structures in which NPs are aggregated or included in other materials. These structures are easily broken in water media by the application of ultrasounds, leading to a stable suspension of insoluble NPs. The contribution of NPs can be evaluated as the difference between the inductively coupled plasma (ICP-MS) analysis before and after the elution of the stable NPs suspension from an ion exchange cartridge.
\end{abstract}

Key words: nanoparticles, elements, airborne particulate matter, dimensional distribution

\section{Introduction}

Nanoparticles (NPs) are released into the ambient air from different natural and anthropic processes, as volcanic eruptions, forest fires, waste incineration and combustion of fossil fuel.

A number of studies are addressed to toxicological properties of NPs, but the level of exposure risk for living species and environment is still largely unknown (Oberdòrster et al., 2005).

Respect to larger particles, NPs are characterized by higher surface area, being then more reactive toward the environment. In the atmosphere, NPs may act as condensation nuclei and are subjected to aggregation processes. In ambient air, most of the nanoparticles are then present as structures with aerodynamic diameters in the range 0.1-1 $\mu \mathrm{m}$ (fine fraction of PM).

As all the instruments used for the measurement of NPs concentration are based on the dimensional selection of particles with diameters below $0,1 \mu \mathrm{m}$, these structures are not included in the measure, leading to an underestimation of the relevance of NPs in ambient air.

In this work we studied the efficiency of the ultrasound (US) application in disaggregating and dispersing insoluble NPs in water.
After a stable suspension of NPs was obtained, we evaluated the NPs contribution to elemental concentration in airborne particulate matter on the basis of a previous study (Canepari et al., 2010), in which Sb-containing NPs were estimated as difference between the concentrations measured by inductively coupled plasma - mass spectrometry (ICP-MS) before and after the elution from a chromatographic column.

\section{Materials and Methods}

The analytical method is summarized in figure 1. Briefly, PM samples were disperded in $3 \mathrm{~mL}$ of deioned water, exposed for 3 hours to US and then filtered (filter porosity $0.22 \mu \mathrm{m})$. The disaggregation efficiency was evaluated by measuring the dimensional distribution (hydrodynamic diameter) of the suspended particles (Zetasizer Nano Series, Malvern Instruments, England).

The filtered fraction was divided into two aliquotes: one was directly analysed by ICP-MS (Varian 820, Mulgrave, Australia), while the other was injected in a chromatograph (Metrohm mod. 761 Compact, Metrohm, Origgio (Va), Italy; loop $500 \mu \mathrm{L}$ ) equipped with an anion exchange cartridge (Metrosep A SUPP 4/5 Guard/4.0, Metrohm, Origgio (Va), Italy) and then analysed by 
ICP-MS.

The filtration residual was subjected to microwave-assisted (Milestone Ethos Touch Control; HPR 1000/6S rotor, Sorisole, BG-ITALY) acid digestion, using a 4:2 $\mathrm{HNO}_{3} / \mathrm{H}_{2} \mathrm{O}_{2}$ mixture (Canepari et al, 2006 and 2008) and analysed by ICP-MS.

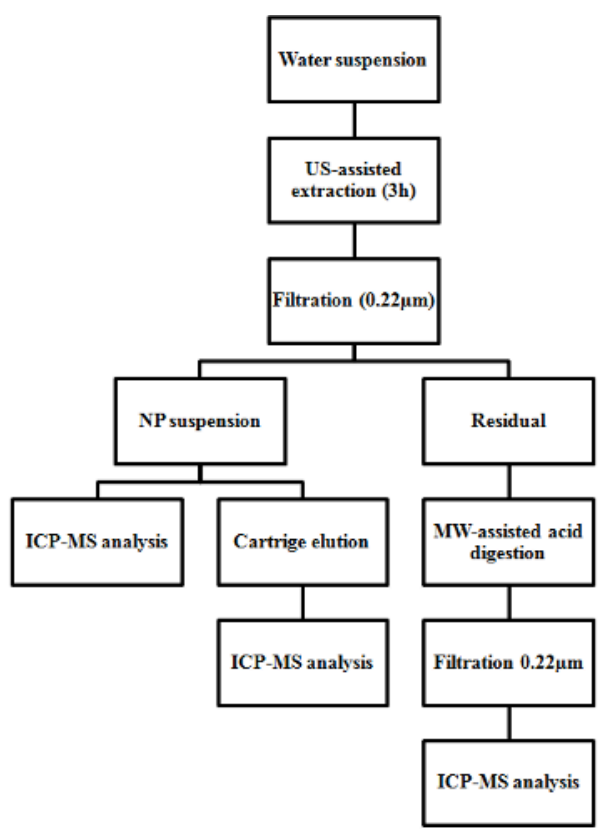

Fig. 1. Scheme of the analytical procedure

Real PM samples were collected during a period of 15 days (spring 2010), at a sampling site located in the area of the University of Rome "La Sapienza", close to the Chemistry Department, about $50 \mathrm{~m}$ from the nearest urban road. We used a 13-stage low-pressure impactor (DLPI, DEKATI Ltd., Tampere, Finland). The instrument operates at the flow rate of $10 \mathrm{~L} \mathrm{~min}^{-1}$ and at the pressure of 100 mbar under the last impactor stage. The nominal values for the equivalent aerodynamic 50\% cut-off diameters of the stages are: $10,6.8,4.4,2.5,1.6,1.0,0.65$, $0.40,0.26,0.17,0.108,0.060$, and $0.030 \mu \mathrm{m}$. PTFE membranes, $25 \mathrm{~mm}$ diameter, (ALBET, Barcelona, Spain) were used as substrates on the collection plates of the impactor.

\section{Results and Discussion}

The results of Dynamic Light Scattering (DLS) measurements showed a decrease of the hydrodynamic diameter of suspended particles with the increase of the US application times. A mean value of about $70 \mathrm{~nm}$ was obtained after 3 hours of US exposure. The obtained suspensions were stable for 2 hours and all the successive treatments of the samples were performed within this time.

Figure 2 shows $\mathrm{Rb}$ and $\mathrm{Cd}$ results in size-segregated PM samples. Rubidium (upper panel) is present in PM samples as soluble species and the concentrations measured before and after the elution from the cartridge are very similar. All the other elements of I and II groups show the same behavior.

The concentrations of $\mathrm{Cd}$ (lower panel) in the solutions eluted from the cartridge are instead significantly lower than those directly measured in the suspension. As previously observed for Sb (Canepari et al., 2010), the retention of solid NPs on the cartridge can account for this behavior.
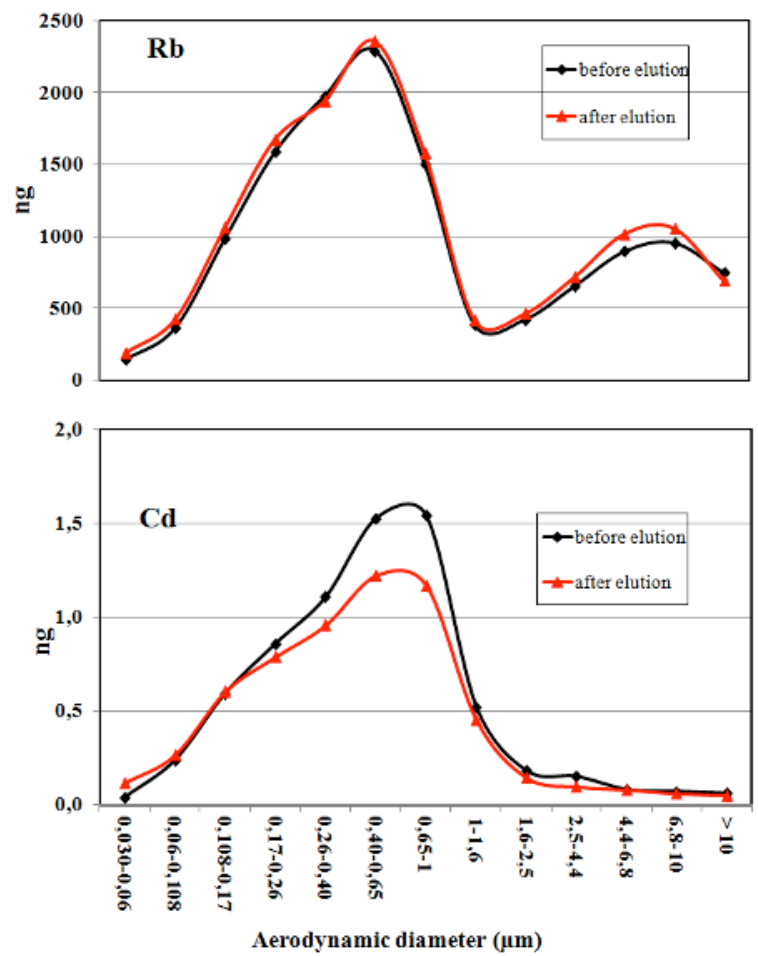

Fig. 2. Concentrations of $\mathrm{Rb}$ (upper panel) and $\mathrm{Cd}$ (lower panel) in size-segregated PM samples before and after the elution from cartridge

It is worth noting that the decrease of $\mathrm{Cd}$ concentrations is evident on the impactor stages related to the fine fraction of PM (aerodynamic diameter up to 1 $\mu \mathrm{m})$, in which the presence of included or aggregated NPs is expected. Most of the elements that are known to be released by combustion sources show results similar to $\mathrm{Cd}$. Figure 3 shows the percentages of elements retained by the cartridge in the fine fractions of PM (sum of the stages up to $1 \mu \mathrm{m})$. As it can be noted, this percentage is of about $15 \%$ for $\mathrm{Cd}$ and higher than $50 \%$ for $\mathrm{V}, \mathrm{Cu}, \mathrm{Sb}, \mathrm{Sn}$ and As, while it is negligible for the other elements.

Particles with higher aerodynamic diameters (coarse fraction), mainly released into the atmosphere by mechanical processes, contain all these elements as soluble species (with no differences between the analysis before and after the elution) or in the filtration residue. This result is in agreement with the different morphological structure of these particles: as they are not nano-structured, after the US application their dimension remain higher than the filter pore dimension. 


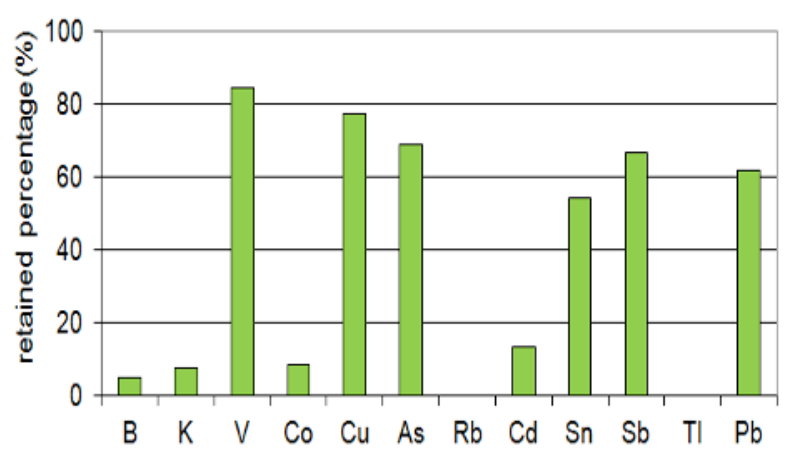

Fig. 3. Percentages of elemental concentration retained by the cartridge.

\section{Conclusions}

We describe a method to estimate the contribution of nanoparticles to the elemental concentration in the fine fraction of airborne particulate matter. Our results indicates that a relevant percentages of $\mathrm{Pb}, \mathrm{Sb}, \mathrm{Sn}, \mathrm{Cd}, \mathrm{V}$ and As are present in PM as insoluble nanoparticles that are subjected to aggregation or inclusion processes during their permanence in the atmosphere. These nanoparticles are easily suspended in water by the application of ultrasound.

\section{Acknowledgements}

The Authors grateful aknowledge Dr. Franco Padella and Dr Valerio Giudi. This work was partially funded by Sapienza University of Rome, in the framework of the Universitary Research Program.

\section{References}

Oberdòrster G, Oberdòrster E, Oberdòrster J. Nanotoxicology: an emerging discipline evolving from studies of ultrafine particles. Environ. Health Perspect. 2005; 113:823-39.

Canepari S, Cardarelli E, Pietrodangelo A, Giuliano A. Determination of metals, metalloids and non-volatile ions in airborne particulate matter by a new two-step sequential leaching procedure. Part A: experimental desgn and optimization. Talanta. 2006; 69:581-587.

Canepari S, Perrino C, Olivieri F, Astolfi ML.

Characterization of the traffic sources of PM through size-segregated sampling, sequential leaching and ICP analysis.Atmos. Environ. 2008. 42; 8161-8175.

Canepari S, Marconi E, Astolfi ML, Perrino C. Relevance of $\mathrm{Sb}(\mathrm{III}), \mathrm{Sb}(\mathrm{V})$, and $\mathrm{Sb}$-containing nano-particles in urban atmospheric particulate matter. Anal. Bioanal. Chem. 2010; 379: 2533-2543. 